\title{
Meta-Analysis of Comparative Trials Evaluating a Prophylactic Single-Use Negative Pressure Wound Therapy System for the Prevention of Surgical Site Complications
}

\author{
Vicki Strugala and Robin Martin
}

\begin{abstract}
Background: We report the first meta-analysis on the impact of prophylactic use of a specific design of negative pressure wound therapy (NPWT) device on surgical site complications.

Methods: Articles were identified in which the specific single-use NPWT device (PICO $\diamond$, Smith \& Nephew) was compared with standard care for surgical site infection (SSI), dehiscence, or length of stay (LOS). Risk ratio (RR) $\pm 95 \%$ confidence interval (CI) (SSI; dehiscence) or mean difference in LOS $\pm 95 \%$ CI was calculated using RevMan v5.3.

Results: There were 1863 patients (2202 incisions) represented by 16 articles. Among 10 randomized studies, there was a significant reduction in SSI rate of $51 \%$ from $9.7 \%$ to $4.8 \%$ with NPWT intervention (RR 0.49 [95\% CI 0.34-0.69] $\mathrm{p}<0.0001)$. There were six observational studies assessing reduction in SSI rate of $67 \%$ from $22.5 \%$ to $7.4 \%$ with NPWT (RR 0. 32 [95\% CI 0.18-0.55] p<0.0001). Combining all 16 studies, there was a significant reduction in SSI of 58\% from $12.5 \%$ to $5.2 \%$ with NPWT (RR 0.43 [95\% CI 0.32-0.57] p $<0.0001$ ). Similar effects were seen irrespective of the kind of surgery (orthopedic, abdominal, colorectal, or cesarean section), although the numbers needed to treat (NNT) were lower in operations with higher frequencies of complications. There was a significant reduction in dehiscence from $17.4 \%$ to $12.8 \%$ with NPWT (RR 0.71 [95\% CI 0.54-0.92] $\mathrm{p}<0.01)$. The mean reduction in hospital LOS by NPWT was also significant $(-0.47$ days [95\% CI -0.71 to -0.23$] \mathrm{p}<0.0001)$.

Conclusions: The significant reduction in SSI, wound dehiscence, and LOS on the basis of pooled data from 16 studies shows a benefit of the PICO single-use NPWT system compared with standard care in closed surgical incisions.
\end{abstract}

Keywords: postoperative complication; prophylaxis; surgical site infection; wound infection; wound management

$\mathbf{I}$ MPROVING OUTCOMES FOR PATIENTS undergoing surgical procedures by reducing rates of surgical site complications (SSC) could have a significant impact on patients' lives and societal and healthcare costs [1]. Complications that may affect closed surgical incisions and ultimately delay healing include surgical site infection (SSI), dehiscence, seroma, and hematoma, and these may result in poor quality or abnormal scar formation. The Centers for Disease Control and Pre- vention (CDC) definitions of SSIs are widely used for surveillance and research purposes. They classify SSIs as superficial incisional, deep incisional, or organ/space and are applicable to all types of operations [2].

Prevention of SSCs is complex because of the interactions of patient-related, environmental, and surgical factors that may be involved. Risk factors may occur at multiple points during the pre-operative, operative, and post-operative phases

Advanced Wound Management, Clinical, Scientific and Medical Affairs, Smith \& Nephew plc, Hull, United Kingdom.

(C) Vicki Strugala and Robin Martin, 2017; Published by Mary Ann Liebert, Inc. This Open Access article is distributed under the terms of the Creative Commons License (http://creativecommons.org/licenses/by/4.0), which permits unrestricted use, distribution, and reproduction in any medium, provided the original work is properly credited. 
of surgical procedures. Efforts to reduce SSI often include a limited number of selected interventions that are grouped together in a "care bundle" [3], but compliance with a care bundle is not assured [4].

Negative pressure wound therapy (NPWT) is emerging as a promising technology as a preventative intervention and is beginning to be advocated within care bundles in a variety of closed surgical incisions to reduce SSC and specifically SSI [1,5-7]. The mode of action of NPWT on a closed surgical incision is notably different from the mode of action in open wounds. The combined effects of reduced lateral tension, improved lymphatic clearance, and reduction in hematoma and seroma, as demonstrated in studies of NPWT on closed surgical incisions, may contribute to faster and stronger healing with reduced risk of infection and dehiscence [6]. Although conventional wisdom might suggest that the NPWT dressing should be targeted just to the sutured incision, there is a developing awareness that the lateral extent of operation may be important and that application of NPWT across a wider surface area ("the zone of injury") may be a better clinical strategy $[1,6,8]$, because NPWT can act to reduce: edema, excess interstitial fluid, and venous stasis and improve the general condition of the adjacent tissue [9-11].

There is a growing body of clinical evidence in which prophylactic NPWT has been investigated to reduce the risk of SSC in controlled studies, and a number of meta-analysis have been performed on this data [5,12-16]. It must be stressed that these previous meta-analyses include a diverse mix of traditional NPWT and single-use NPWT devices operating at varying levels of negative pressure and mixed surgical indications, which may introduce heterogeneity into meta-analysis.

\section{Aim}

We report the first meta-analysis on SSC occurrence using a specific single-use or disposable NPWT device (PICO single-use NPWT system, Smith \& Nephew, Hull, UK) that operates only at $-80 \mathrm{~mm} \mathrm{Hg}$ with the aim of reducing two key variables that are responsible for heterogeneity when different devices are combined. The influence of this specific NPWT device on the rate of SSI, dehiscence, and length of stay (LOS) has been analyzed in comparison with standard care across a number of surgical indications. Disposable or single-use NPWT devices are particularly attractive for preventative use [6]. Figure 1 shows the PICO device in use.

\section{Methods}

This systematic review and meta-analysis is reported in accordance with the Preferred Reporting Items for Systematic reviews and Meta-Analyses (PRISMA) statement [17].

\section{Eligibility criteria}

All known clinical studies comparing single-use NPWT with standard care (any non-NPWT dressing) applied post-operatively on a closed surgical incision were included. The intervention was required to be the PICO single-use NPWT system, which is a small canister-free device that deals with exudate by absorption and evaporation using a unique dressing technology. It delivers $-80 \mathrm{~mm} \mathrm{Hg}$ negative pressure (nominal) for seven days.

Participants of any age and undergoing any type of operation were eligible. There were no restrictions on the inclu-

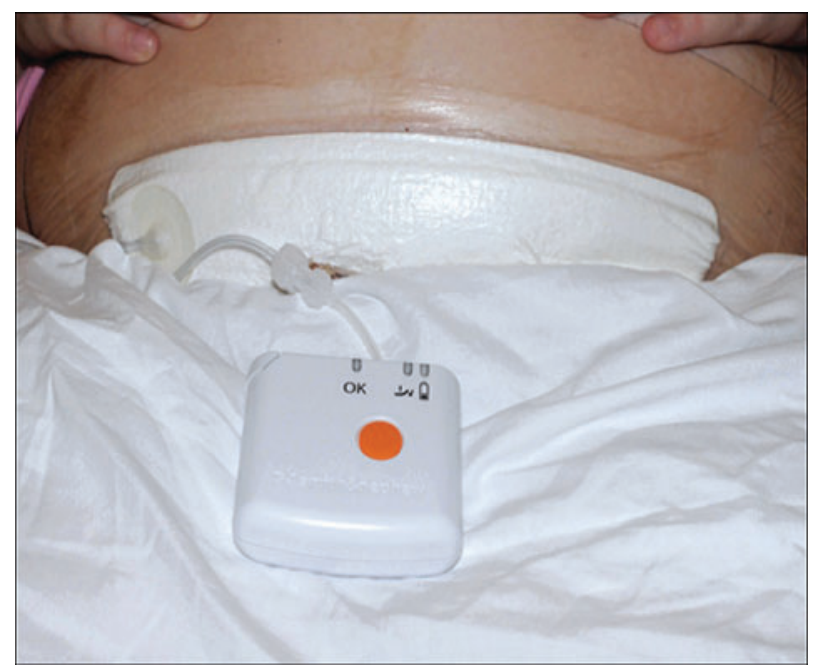

FIG. 1. The $\mathrm{PICO}^{\diamond}$ single use negative pressure wound therapy in position on a patient with a cesarean section closed surgical incision. PICO (Smith \& Nephew) is a small, lightweight, ultra-portable, negative pressure system that consists of a dressing, supplied with a small negative pressure pump powered by two AA batteries. The pump is disposable after seven days. The PICO system produces negative pressure at $-80 \mathrm{~mm} \mathrm{Hg}$ continuously, and therapy can be started or paused using the single orange button [53]. Used with permission from Bullogh and Burns [23].

sion or exclusion criteria with regard to risk factors for complications. Studies had to report either SSI with at least 21 days follow-up, wound dehiscence occurrence, or the LOS (days). Eligible clinical studies could be randomized controlled trials (RCT), retrospective or prospective observational studies, and be of any sample size. No publication restrictions were imposed. Published abstracts or $\mathrm{PhD}$ thesis with sufficient information to extract mean and variance data were included. No valid study was excluded. Studies that were not in English, participants were not human, or case reports, case-series, letters, commentaries, notes, or editorials were excluded. Whenever multiple publications of the same data existed, only the most inclusive, comprehensive, and recent one was included.

\section{Search strategy}

A database of all publications in which PICO single-use NPWT was mentioned was compiled. The search strategy was:

- PubMed search (search terms: Negative pressure wound therapy [Title/Abstract] OR Pico [Title/Abstract] OR Renasys [Title/Abstract] OR VAC [Title/ Abstract] OR prevena [Title/Abstract] OR NPWT [Title/Abstract] OR topical negative pressure [Title/Abstract] OR incisional NPWT [Title/Abstract]).

- Review of content from key wound conferences or surgical speciality conferences (e.g. EWMA, WUWHS, SAWC, Wounds UK).

- Intelligence from Clinicaltrials.gov registry or country equivalents (search terms: $\mathrm{PICO}{ }^{\diamond}$ AND NPWT OR NPWT) with extraction of study information, including the title, brief description, conditions, interventions, locations and principal investigator. 
This systematic review and meta-analysis were based on that $\mathrm{PICO}^{\diamond}$ database and search terms listed from 2011 up to March 31, 2017. Review of the publications that met the eligibility criteria was performed by two independent reviewers (VS and RM).

\section{Data extraction}

Data were extracted on the number of patients (or more precisely, the number of incisions), type of surgical procedure, duration of prophylactic NPWT, clinical end-points, and frequency of those outcomes (SSI or dehiscence). The mean ( \pm SD [standard deviation]) LOS was also extracted (or derived by calculation from other reported averages and variance). The type of study was noted as either RCT (including interim or pilot) or observational for non-randomized comparative studies.

\section{Data analysis}

Meta-analysis was performed using a fixed effects model in Review Manager (RevMan) software Version 5.3. (Copenhagen: The Nordic Cochrane Centre, The Cochrane Collaboration, 2014). Dichotomous data were analyzed using Mantel-Haenszel (M-H) [18] to calculate risk ratio (RR) $\pm 95 \%$ confidence interval $(\mathrm{CI})$. For continuous data, mean (SD) was entered and was analyzed by Inverse Variance to calculate mean difference $\pm 95 \%$ CI. Level of heterogeneity across studies was noted by the $\mathrm{I}_{2}$ statistic, and random effects meta-analyses modeling was also reported [19].
For the SSI studies, the data were analyzed as (1) RCTs only, (2) observational studies only, (3) all studies combined (overall). Subgroup meta-analyses stratified by type of surgical procedure were performed subsequently. Number needed to treat (NNT) to avoid a complication was calculated. Data are presented as forest plots, and study bias evaluation was presented as a funnel plot.

\section{Results}

\section{Study selection}

On the basis of a review of a comprehensive database of 64 articles, 88 posters/abstracts, and one $\mathrm{PhD}$ thesis, we selected 26 articles for full text review (Fig. 2 shows the flow chart of the selection of articles for the meta-analysis). After exclusion of eight articles [20-27], finally 18 articles in which PICO was compared with standard care were used in the final qualitative review [8,28-44]. Two articles did not go on to the quantitative meta-analysis because of the SSC endpoints not meeting the selection criteria for analysis $[8,37]$. One article described two separate patient populations (breast and colorectal surgery) that were assessed and analyzed separately [40].

\section{Study characteristics}

All studies used the PICO single-use NPWT system. In the quantitative meta-analysis, there were 16 articles (1863 patients) comprising $10 \mathrm{RCTs}$ reported in 10 articles (including 1734 incisions) and seven observational studies reported in

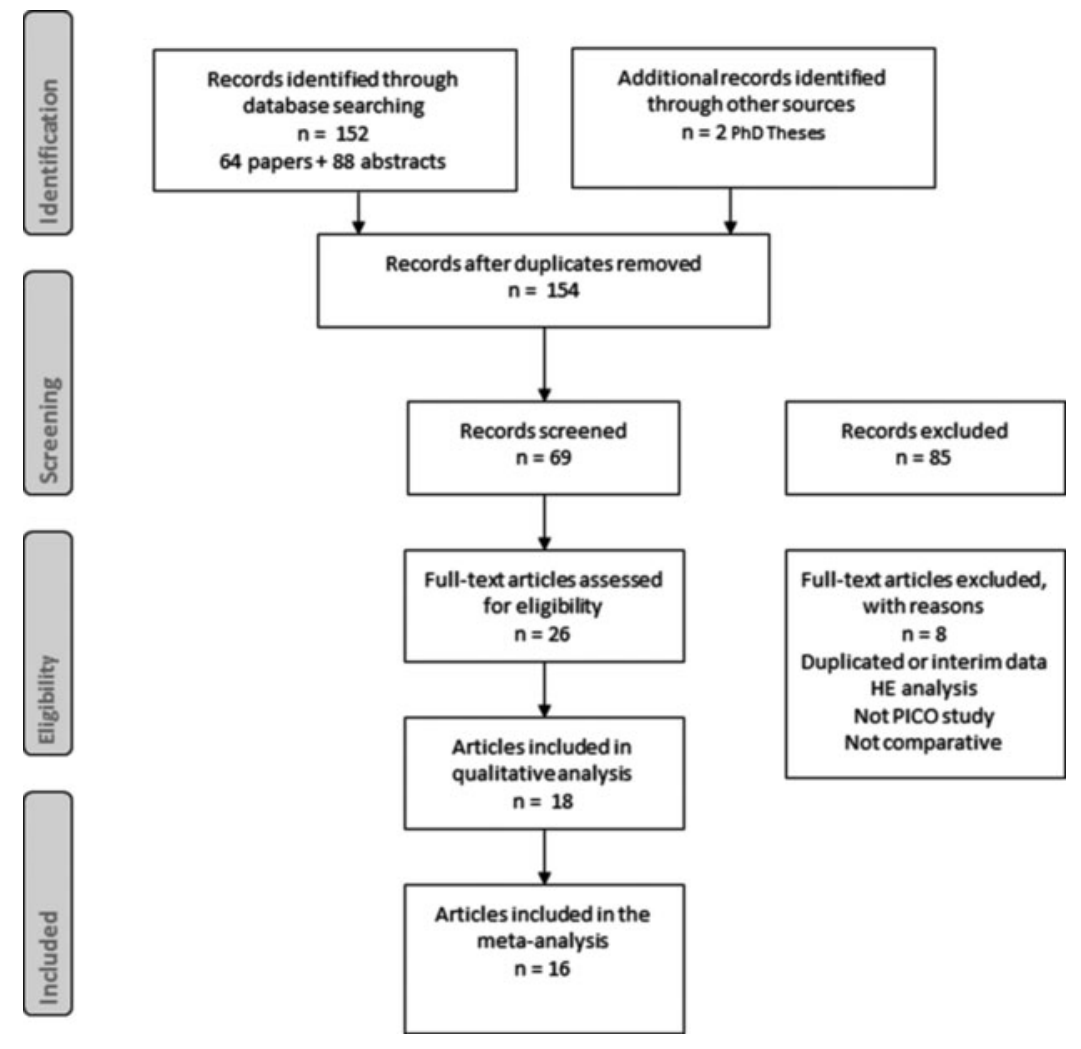

FIG. 2. The Preferred Reporting Items for Systematic reviews and Meta-Analyses flowchart showing selection of articles for the meta-analysis. 
Table 1. Characteristics of Studies Included in Quantitative Review

\begin{tabular}{|c|c|c|c|c|c|}
\hline Reference & $\begin{array}{c}\text { Type of surgical } \\
\text { procedure }\end{array}$ & Study design & $\begin{array}{l}\text { Specific } \\
\text { risk factor }\end{array}$ & $\begin{array}{l}\text { Duration } \\
\text { of PICO } \\
\text { treatment }\end{array}$ & $\begin{array}{c}\text { Outcome measures } \\
\text { (day measured); } \\
\text { meta-analysis outcomes } \\
\text { in bold }\end{array}$ \\
\hline $\begin{array}{l}\text { Adogwa } \\
\text { et al } 2014 \text { [28] }\end{array}$ & $\begin{array}{l}\text { Spinal surgical } \\
\text { procedure for } \\
\text { thoracolumbar } \\
\text { fusion }\end{array}$ & Retrospective & & $3 \mathrm{~d}$ & $\begin{array}{l}\text { SSI }(30 \mathrm{~d}) \\
\text { Dehiscence }(90 \mathrm{~d}) \\
\text { SSI }(90 \mathrm{~d}) \\
\text { Readmission rate }(30 \mathrm{~d}) \\
\text { Return to operating theater }\end{array}$ \\
\hline $\begin{array}{l}\text { Chayboyer } \\
\text { et al } 2014 \text { [29] }\end{array}$ & C-section & RCT—pilot & $\mathrm{BMI} \geq 30$ & $4 \mathrm{~d}$ & $\begin{array}{l}\text { SSI }(30 \mathrm{~d}) \\
\text { Type of SSI }(30 \mathrm{~d}) \\
\text { Other wound } \\
\quad \text { complications }(30 \mathrm{~d}) \\
\text { LOS } \\
\text { Readmission }(28 \mathrm{~d})\end{array}$ \\
\hline $\begin{array}{l}\text { Galiano } \\
\quad \text { et al } 2014[30]^{\mathrm{a}}\end{array}$ & $\begin{array}{l}\text { Breast reduction } \\
\text { mammoplasty }\end{array}$ & $\begin{array}{l}\mathrm{RCT} \text {-multicenter } \\
\text { bilateral study }\end{array}$ & & $7-14 \mathrm{~d}$ & $\begin{array}{l}\text { All complications }(21 \mathrm{~d}) \\
\text { Delayed healing }(7 \text { days } \\
\quad \text { and } 10 \mathrm{~d}) \\
\text { Dehiscence }(21 \mathrm{~d}) \\
\text { SSI }(21 \mathrm{~d}) \\
\text { Scar quality }\end{array}$ \\
\hline $\begin{array}{l}\text { Gillespie } \\
\quad \text { et al } 2015[31]\end{array}$ & $\begin{array}{l}\text { Primary hip } \\
\text { arthroplasty }\end{array}$ & RCT—pilot & & $5 \mathrm{~d}$ & $\begin{array}{l}\text { SSI }(42 \mathrm{~d})^{\mathrm{b}} \\
\text { SSI indicators }(42 \mathrm{~d}) \\
\text { Wound complications }(42 \mathrm{~d}) \\
\text { LOS } \\
\text { Readmission }\end{array}$ \\
\hline $\begin{array}{l}\text { Hasselmann } \\
\quad \text { et al } 2015 \text { [32] }\end{array}$ & $\begin{array}{l}\text { Vascular surgical } \\
\text { procedure }\end{array}$ & $\begin{array}{l}\text { RCT_-interim } \\
\text { partially } \\
\text { bilateral study }\end{array}$ & $\begin{array}{l}\text { Groin } \\
\text { incision, }\end{array}$ & $7 \mathrm{~d}$ & $\begin{array}{l}\text { SSI }(90) \\
\text { Wound complications }(90 \mathrm{~d})\end{array}$ \\
\hline $\begin{array}{l}\text { Hester et al } \\
\quad 2015[33]\end{array}$ & $\begin{array}{l}\text { Revision hip or knee } \\
\text { arthroplasty }\end{array}$ & Retrospective & & $7 \mathrm{~d}$ & $\begin{array}{l}\text { SSI ( } 42 \text { d requiring } \\
\text { operation or antibiotics) } \\
\text { Dressing related } \\
\text { complications }\end{array}$ \\
\hline $\begin{array}{l}\text { Holt \& Murphy } \\
\quad 2015 \text { [34] }\end{array}$ & $\begin{array}{l}\text { Breast therapeutic } \\
\text { mammoplasty and } \\
\text { symmetrizing } \\
\text { reduction }\end{array}$ & $\begin{array}{l}\text { Prospective } \\
\text { Bilateral study }\end{array}$ & & $6 \mathrm{~d}$ & $\begin{array}{l}\text { Dehiscence ( } 6 \mathrm{~d} \text { and } 12 \mathrm{~d} \text { ) } \\
\text { Healing time }\end{array}$ \\
\hline Hyldig 2016 [35] & C-section & RCT-interim & $\mathrm{BMI} \geq 30$ & $5 \mathrm{~d}$ & $\begin{array}{l}\text { SSI }(30 \text { d requiring } \\
\text { antibiotic treatment }) \\
\text { Dehiscence } \\
\text { Exudate }\end{array}$ \\
\hline $\begin{array}{l}\text { Karlakki } \\
\quad \text { et al } 2016 \text { [36] }\end{array}$ & $\begin{array}{l}\text { Primary hip or knee } \\
\text { arthroplasty }\end{array}$ & RCT & & $7 \mathrm{~d}$ & $\begin{array}{l}\text { LOS } \\
\text { Surgical site } \\
\quad \text { complications } \\
\quad \text { (including SSI) }(42 \mathrm{~d})^{\mathrm{c}} \\
\text { Exudate } \\
\text { Dressing changes }\end{array}$ \\
\hline $\begin{array}{l}\text { Matsumoto and } \\
\text { Parekh } 2015 \text { [38] }\end{array}$ & $\begin{array}{l}\text { Primary ankle } \\
\text { arthroplasty }\end{array}$ & Retrospective & & $6 \mathrm{~d}$ & $\begin{array}{l}\text { Wound healing } \\
\text { problems }(21 \mathrm{~d}) \\
\text { SSI }(30 \mathrm{~d})\end{array}$ \\
\hline $\begin{array}{l}\text { O’Leary et al } \\
2016 \text { [30] }\end{array}$ & $\begin{array}{l}\text { Laparotomy for } \\
\text { colorectal or } \\
\text { gynecological } \\
\text { operation }\end{array}$ & $\mathrm{RCT}$ & & $4 \mathrm{~d}$ & $\begin{array}{l}\text { SSI }(30 \mathrm{~d}) \\
\text { SSI }(4 \mathrm{~d}) \\
\text { LOS } \\
\text { Patient satisfaction }\end{array}$ \\
\hline $\begin{array}{l}\text { Pellino et al } \\
2014[40]\end{array}$ & $\begin{array}{l}\text { Colorectal operation } \\
\text { and breast } \\
\text { surgical procedure }\end{array}$ & Prospective & & $7 \mathrm{~d}$ & $\begin{array}{l}\text { SSI }(30 \mathrm{~d}) \\
\text { ASEPSIS score } \\
\text { Seroma } \\
\text { LOS }\end{array}$ \\
\hline $\begin{array}{l}\text { Selvaggi et al } \\
2014[41]\end{array}$ & $\begin{array}{l}\text { Colorectal } \\
\text { operation }\end{array}$ & Prospective & $\begin{array}{l}\text { Crohn disease } \\
\quad \text { (structuring) }\end{array}$ & $7 \mathrm{~d}$ & $\begin{array}{l}\text { SSI }(30 \mathrm{~d}) \\
\text { ASEPSIS score } \\
\text { Seroma } \\
\text { LOS }\end{array}$ \\
\hline
\end{tabular}


TABle 1. (CONTINUED)

\begin{tabular}{|c|c|c|c|c|c|}
\hline Reference & $\begin{array}{c}\text { Type of surgical } \\
\text { procedure }\end{array}$ & Study design & $\begin{array}{l}\text { Specific } \\
\text { risk factor }\end{array}$ & $\begin{array}{l}\text { Duration } \\
\text { of } \mathrm{PICO}^{\diamond} \\
\text { treatment }\end{array}$ & $\begin{array}{c}\text { Outcome measures } \\
\text { (day measured); } \\
\text { meta-analysis outcomes } \\
\text { in bold }\end{array}$ \\
\hline $\begin{array}{l}\text { Tuuli et al } \\
2017 \text { [42] }\end{array}$ & C-section & RCT_pilot & $\mathrm{BMI} \geq 30$ & $4 \mathrm{~d}$ & $\begin{array}{l}\text { SSC }(30) \\
\text { SSI }(30 \mathrm{~d}) \\
\text { Dehiscence }(30 \mathrm{~d}) \\
\text { Seroma }(30 \mathrm{~d}) \\
\text { Hematoma }(30 \mathrm{~d}) \\
\text { Pain score }(2 \mathrm{~d})\end{array}$ \\
\hline $\begin{array}{l}\text { Uchino et al } \\
2016 \text { [43] }\end{array}$ & $\begin{array}{l}\text { Ileostomy closure by } \\
\text { purse string suture }\end{array}$ & RCT_feasibility & & $14 \mathrm{~d}^{\mathrm{d}}$ & $\begin{array}{l}\text { Time to complete } \\
\text { wound healing } \\
\text { SSI }(30 \mathrm{~d})\end{array}$ \\
\hline $\begin{array}{l}\text { Witt-Majchrzak } \\
\text { et al } 2014 \text { [44] }\end{array}$ & $\begin{array}{c}\text { Coronary artery bypass } \\
\text { graft (sternotomy) }\end{array}$ & RCT & & $5-6 d$ & $\begin{array}{l}\text { SSC } \\
\text { SSI }(30 \mathrm{~d})\end{array}$ \\
\hline
\end{tabular}

${ }^{\mathrm{a}}$ Full manuscript of this abstract/poster submitted.

${ }^{\mathrm{b}}$ Per protocol method of analysis calculated as an ITT NPWT; patient was wrongly given standard care and developed an SSI. Published ITT values $=2 / 35(5.7 \%)$ NPWT; $3 / 35(8.6 \%)$ standard care.

${ }^{\mathrm{c}} \mathrm{SSC}$ rates provided but listed complications in detail such that SSI rate can be calculated. Published SSC rates $=2 / 102(2.0 \%)$ NPWT; 9 / $107(8.4 \%)$ standard care.

${ }^{\mathrm{d}} \mathrm{PICO}^{\diamond}$ applied $24 \mathrm{~h}$ after operation.

$\mathrm{SSI}=$ surgical site infection; $\mathrm{RCT}=$ randomized controlled trial; $\mathrm{BMI}=$ body mass index; LOS =length of stay; SSC $=$ surgical site complication; ITT = intention to treat; NPWT = negative pressure wound therapy.

Articles not included in quantitative assessment $[8,37]$.

six articles (including 468 incisions). The characteristics of each included study are displayed in Table 1.

\section{Synthesis of results}

SSI. The rate of SSI was reported in 15 articles representing 16 studies and 1839 patients and comprising 2154 incisions [28-33,35,36,38-44]; the summary statistics of the analysis are shown in Table 2.

On the basis of the 10 RCTs of varying patient numbers, there was a significant reduction in the relative risk of SSI with $\mathrm{PICO}^{\diamond}$ treatment compared with standard care from $9.7 \%$ to $4.8 \%$, which represents an absolute reduction of $4.9 \%$ and a relative reduction of $51 \%$ (fixed effects RR 0.49 [95\% CI 0.34-0.69] $\mathrm{p}<0.00001)$.

In comparison, there were six studies that assessed the SSI rate with non-randomized observational methodology, and these also noted a significant reduction in relative risk of SSI with PICO treatment compared with standard care- $22.5 \%$ to $7.4 \%$-which is a $15.1 \%$ absolute reduction and $67 \%$ relative reduction (fixed effects RR 0.32 [95\% CI 0.18-055] $\mathrm{p}<0.00001)$.
Overall, combining RCT and observational studies, the rate of SSI was 5.2\% (54/1037) with PICO single-use NPWT treatment compared with $12.5 \%(140 / 1117)$ in the standard care group equating to an absolute reduction of $7.3 \%$ and a relative reduction of $58 \%$ (fixed effects RR 0.43 [95\% CI $0.32-0.57] \mathrm{p}<0.0001)$.

The details of each individual study and the RCT, observation, and overall data analysis (as a forest plot) are shown in Figure 3. The optimum estimate of the effect was obtained using the strong RCT evidence because there were more studies.

A subgroup analysis was performed on the basis of individual surgical specialities if three or more studies existed (Table 3). Significant reductions in SSI risk compared with standard care was seen in orthopedic surgical procedures (RR 0.48 [95\% CI 0.25-0.94] p =0.03), abdominal operations (RR 0.44 [95\% CI 0.30-0.64] p <0.0001), colorectal surgical procedures (RR 0.29 [95\% CI 0.15-0.57] $\mathrm{p}=0.0004$ ), and cesarean section (RR 0.53 [95\% CI $0.33-$ $0.84] \mathrm{p}=0.007)$. The degree of relative reduction in the SSI rate was similar $(49 \%-71 \%)$ irrespective of the inherent SSI rate of the surgical procedure; however, the NNT is

Table 2. Summary of Surgical Site Complications Clinical Outcomes of PICO $\diamond$ Single-Use Negative Pressure Wound Therapy Compared with Standard Care

\begin{tabular}{lcccccrr}
\hline & $\begin{array}{c}\text { Risk with } \\
\text { PICO }\end{array}$ & $\begin{array}{c}\text { Risk with } \\
\text { standard care }\end{array}$ & $\begin{array}{c}\text { Relative } \\
\text { reduction }\end{array}$ & $\begin{array}{c}\text { Number } \\
\text { patients }\end{array}$ & $\begin{array}{c}\text { Risk ratio } \\
(95 \% \text { CI) }\end{array}$ & $I_{2}$ & NNT \\
\hline SSI-RCT & $4.8 \%$ & $9.7 \%$ & $51 \%$ & 1734 & $0.49(0.34$ to 0.69$)$ & $9 \%$ & 20 \\
SSI-Observational & $7.4 \%$ & $22.5 \%$ & $67 \%$ & 420 & $0.32(0.18$ to 0.55$)$ & $0 \%$ & 7 \\
SSI-Overall & $5.2 \%$ & $12.5 \%$ & $58 \%$ & 2154 & $0.43(0.32$ to 0.57$)$ & $7 \%$ & 14 \\
Dehiscence-Overall & $12.8 \%$ & $17.4 \%$ & $26 \%$ & 1291 & $0.71(0.54$ to 0.92$)$ & $0 \%$ & 22 \\
\hline
\end{tabular}

$*=$ incisions

$\mathrm{CI}=$ confidence interval; $\mathrm{NNT}=$ number needed to treat; $\mathrm{SSI}=$ surgical site infection; $\mathrm{RCT}=$ randomized controlled trial . 


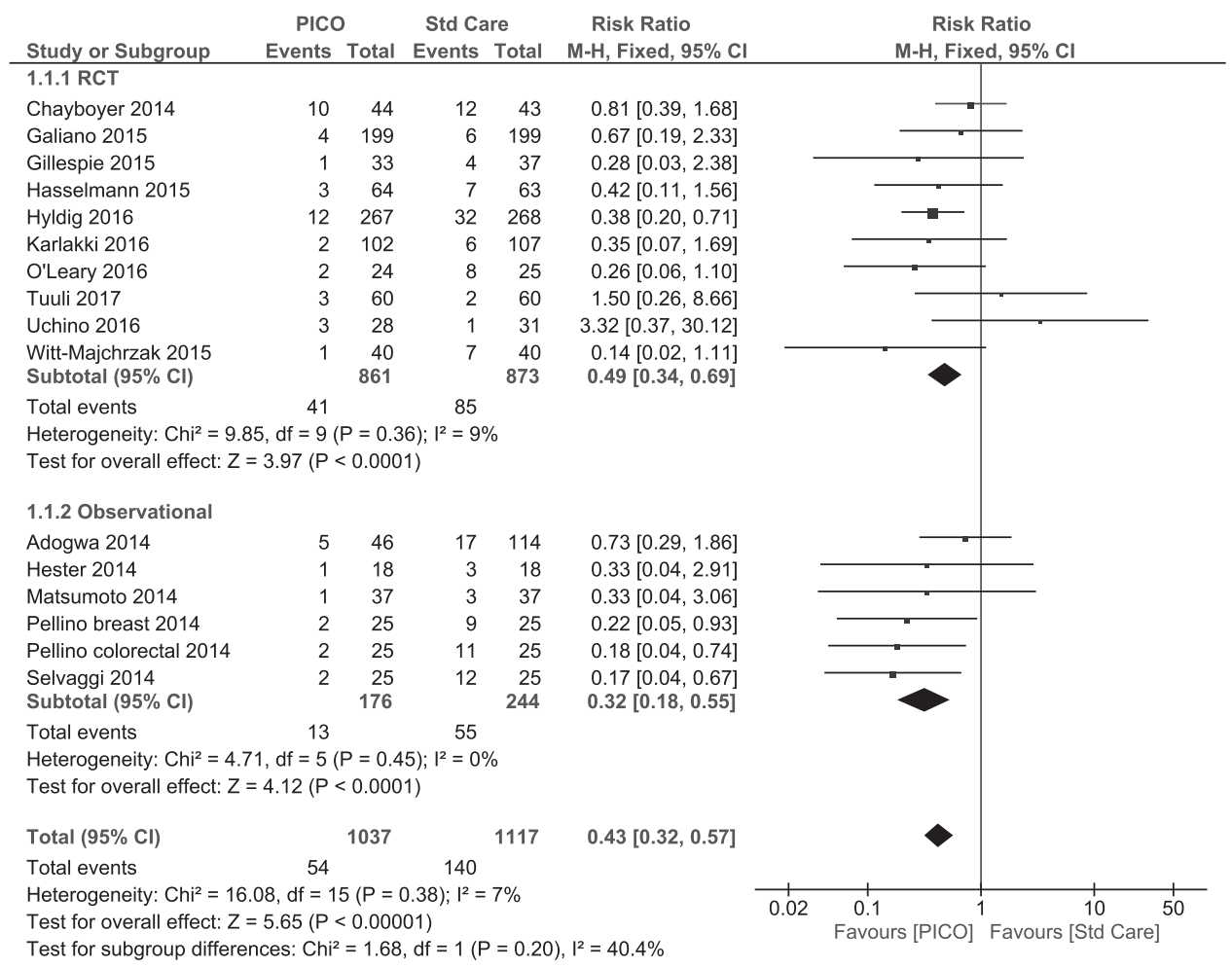

FIG. 3. Forest plot of the comparison of PICO single-use negative pressure wound therapy compared with standard care on surgical site infection outcome by randomized controlled trial (RCT), observational, and overall. Random effects model risk ratio 0.45 (95\% confidence interval $0.32-0.62$ ) overall.

lower in the operations with the higher frequencies of complication.

Dehiscence. Rate of wound dehiscence was reported in six articles and 1068 patients, comprising 1291 incisions $[28,30,31,34,35,44]$. The rate of dehiscence was $12.8 \%$ (78/611) with PICO single-use NPWT treatment compared with $17.4 \%(118 / 680)$ in the standard care group (Table 2) relating to an absolute reduction of $4.6 \%$ and a relative reduction of $26.4 \%$. There was a significant reduction in the relative risk of dehiscence with PICO treatment compared with standard care (fixed effects RR 0.71 [95\% CI $0.54-0.92] \mathrm{p}=0.01$ ). The details of each individual study and the overall data analysis (as a forest plot) are shown in Figure 4.

LOS. The LOS was reported in eight studies representing 725 patients $[28,29,31,36,39-41]$. There was a significant mean difference in LOS from PICO single-use NPWT treatment compared with standard care $(-0.47$ days $[95 \% \mathrm{CI}$ -0.71 to -0.23 ] $\mathrm{p}<0.0001)$. The detail of each individual study and the overall data and subgroup analysis (as a forest plot) is shown in Figure 5. A subgroup analysis was performed on the basis of surgical speciality, and mean difference in LOS was -5.1 days in colorectal/laparotomy surgical procedures [39-41] but only -0.1 days in all other operations $[28,29,31,36,40]$.

\section{Publication bias}

An assessment of the publication bias on the basis of the 15 articles included for an SSI outcome is shown in the funnel plot (Fig. 6). The distribution of studies is symmetric, suggesting no publication bias. because both large and small (pilot/ feasibility) studies regardless of the outcome are being published.

Table 3. Summary of Surgical Site Infection Clinical Outcome of PiCO ${ }^{\diamond}$ Single-Use Negative Pressure

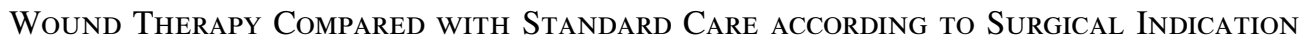

\begin{tabular}{lcccccr}
\hline Surgical procedure & $\begin{array}{c}\text { Risk with } \\
\text { PICO }\end{array}$ & $\begin{array}{c}\text { Risk with } \\
\text { standard care }\end{array}$ & $\begin{array}{c}\text { Relative } \\
\text { reduction }\end{array}$ & $\begin{array}{c}\text { Number } \\
\text { studies }\end{array}$ & $\begin{array}{c}\text { Risk ratio } \\
\text { (95\% CI) }\end{array}$ & NNT \\
\hline Orthopedic - Reconstruction & $4.2 \%$ & $10.5 \%$ & $60 \%$ & 5 & $0.48(0.25$ to 0.93$)$ & 16 \\
Colorectal & $8.8 \%$ & $30.2 \%$ & $71 \%$ & 4 & $0.29(0.15$ to 0.57) & 5 \\
Cesarean section & $6.7 \%$ & $13.2 \%$ & $49 \%$ & 3 & $0.53(0.33$ to 0.84) & 15 \\
Abdominal (colorectal + C-section) & $7.2 \%$ & $16.4 \%$ & $56 \%$ & 7 & 0.44 (0.30 to 0.64) & 11 \\
\hline
\end{tabular}

$\mathrm{CI}=$ confidence interval; $\mathrm{NNT}=$ number needed to treat. 


\begin{tabular}{|c|c|c|c|c|c|c|c|c|c|}
\hline Study or Subgroup & \multicolumn{2}{|c|}{ PICO } & \multicolumn{2}{|c|}{ Std Care } & \multirow{2}{*}{ Weight } & \multirow{2}{*}{$\begin{array}{c}\begin{array}{c}\text { Risk Ratio } \\
\text { M-H, Fixed, 95\% Cl }\end{array} \\
0.53[0.16,1.76]\end{array}$} & \multicolumn{2}{|c|}{$\begin{array}{c}\text { Risk Ratio } \\
\text { M-H, Fixed, } 95 \% \mathrm{Cl}\end{array}$} & \\
\hline Adogwa 2014 & 3 & 46 & 14 & 114 & & & & & \\
\hline Galiano 2015 & 32 & 199 & 52 & 199 & $46.4 \%$ & $0.62[0.41,0.91]$ & - & & \\
\hline Gillespie 2015 & 1 & 35 & 1 & 35 & $0.9 \%$ & $1.00[0.07,15.36]$ & & & \\
\hline Holt 2015 & 1 & 24 & 4 & 24 & $3.6 \%$ & $0.25[0.03,2.08]$ & & & \\
\hline Hyldig 2016 & 40 & 267 & 46 & 268 & $41.0 \%$ & $0.87[0.59,1.29]$ & $\rightarrow$ & & \\
\hline Witt-Majchrzak 2015 & 1 & 40 & 1 & 40 & $0.9 \%$ & $1.00[0.06,15.44]$ & & & \\
\hline Total $(95 \% \mathrm{Cl})$ & & 611 & & 680 & $100.0 \%$ & $0.71[0.54,0.92]$ & & & \\
\hline Total events & 78 & & 118 & & & & & & \\
\hline $\begin{array}{l}\text { Heterogeneity: } \mathrm{Chi}^{2}= \\
\text { Test for overall effect }\end{array}$ & $\begin{array}{l}87, \mathrm{df}=5 \\
=2.56(\mathrm{~F}\end{array}$ & $\begin{array}{l}5(P=0 \\
=0.0\end{array}$ & 1) 72$) ; 1^{2}=$ & & & & $\begin{array}{lc}0.05 & 0.2 \\
& \text { Favours [PICO] }\end{array}$ & $\begin{array}{lr}1 & 5 \\
15 & \text { Favours IS }\end{array}$ & $\begin{array}{r}2 \\
\text { Care }\end{array}$ \\
\hline
\end{tabular}

FIG. 4. Forest plot of the comparison of $\mathrm{PICO}^{\diamond}$ single-use negative pressure wound therapy compared with standard care on dehiscence outcome. Random effects model RR 0.72 (95\% CI 0.55-0.93).

\section{Discussion}

On the basis of 16 published clinical papers in which the PICO single-use NPWT device was compared with standard care, there was a clear and significant benefit in favor of prophylactic NPWT to reduce SSI, wound dehiscence, and LOS when the device was applied on a closed surgical incision. The SSCs may delay healing and result in considerable morbidity, death, and socioeconomic costs, and up to $60 \%$ are considered to be preventable [1]. There is now also an argument that SSC, and SSI in particular, could have a detrimental effect on oncologic survival [45-47]. The PICO single-use NPWT is shown to be an intervention that reduces SSC and therefore the socioeconomic sequelae.

This is the first comprehensive meta-analysis that has assessed the impact of a specific design of NPWT system on SSCs. By limiting the meta-analysis to a single brand of NPWT with a fixed level of negative pressure $(-80 \mathrm{~mm} \mathrm{Hg})$, some heterogeneity was reduced. There still remains a heterogeneous mix of surgical indications and patient profiles but the sub-group analysis confirms that the benefit of PICO on SSI remains with stratification. On the basis of the $\mathrm{I}_{2}$ statistic, it confirms the homogenous study population and strengthens the conclusions that can be made $\left(I_{2}=9 \%\right.$ for 10 RCTs, $0 \%$ for six observational studies, and $7 \%$ for the combined 16 studies). Other reviews and meta-analyses have included a diverse mix of traditional NPWT and single-use NPWT devices, varying levels of negative pressure, and varying materials/fillers. There was also calculation of an effect on dehiscence again with a homogenous study population $\left(I_{2}=0 \%\right)$. On the basis of a higher level of heterogeneity in the LOS data $\left(I_{2}=94 \%\right.$ when 8 studies combined), however, the conclusions for this specific analysis need to be downgraded but show it is worth investigating LOS further.

De Vries et al [15] published recently the supporting metaanalysis data for prophylactic use of NPWT on SSI risk as part of the World Health Organization recommendations for SSI prevention [7]. They stratified their meta-analysis by RCT and also by comparative observational studies, like our study. They reviewed six RCTs and reported a reduction in SSI with RR 0.56. Their observational study analysis comprised 15 studies, and they noted decrease in SSI rate with RR 0.29.

The PICO-only data in this present analysis confirm that this specific design operating at $-80 \mathrm{~mm} \mathrm{Hg}$ is proven to reduce the incidence of SSI across several surgical indications. This echoes the W.H.O. conditional recommendations that suggest the use of prophylactic NPWT on primarily closed surgical incisions in high-risk wounds for the purpose of preventing SSI, taking resources into account [7]. It also supports consensus findings that advocate the prophylactic use of NPWT on closed surgical incisions when either patient or procedure risk factors exist [1].

To support the widespread adoption of the use of prophylactic NPWT, of course there needs to be supporting health economic evidence to show that investing in prevention delivers a net benefit for patients and healthcare systems.

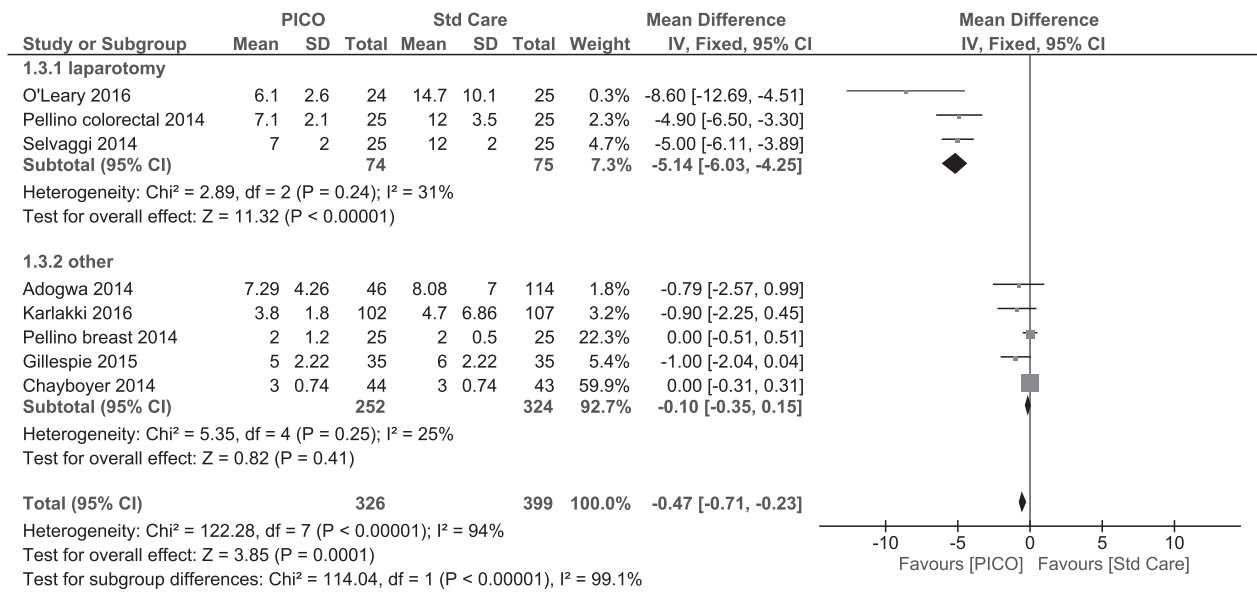

FIG. 5. Forest plot of the comparison of $\mathrm{PICO}^{\diamond}$ single-use negative pressure wound therapy compared with standard care on length of stay with subgroup analysis. Random effects model for all surgical procedures -2.15 (95\% CI -3.46 to -0.84$)$. 


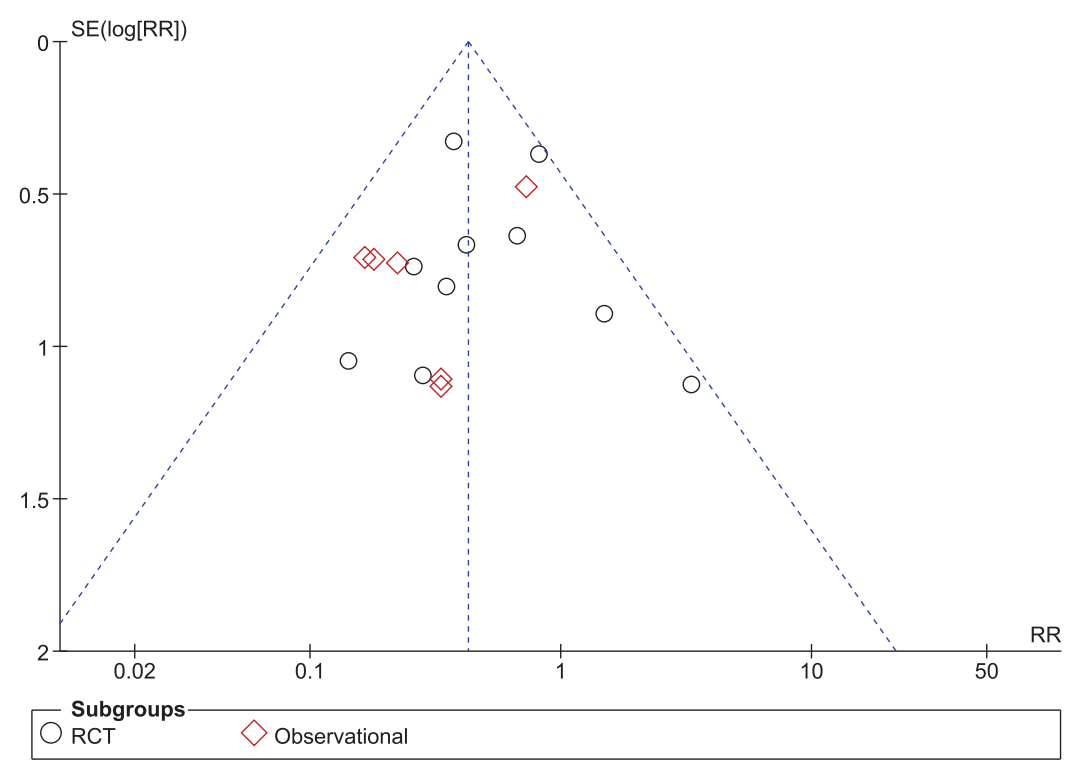

FIG. 6. Funnel plot of comparison $\mathrm{PICO}^{\diamond}$ single-use negative pressure wound therapy compared with standard care on surgical site infection outcomes. $\mathrm{SE}=$ standard error; $\mathrm{RR}=$ risk ratio; $\mathrm{RCT}=$ randomized controlled trial.

These studies are now emerging [27,48]. At an approximate cost of \$225 for a week of preventative NPWT (April 2017) and modest numbers for NNT, PICO single-use NPWT may prove to be a cost-effective tool in the reduction of surgical complications.

This is a fast moving field. Even with this specific design of single-use NPWT device, new studies are being published regularly, and there are many studies ongoing as noted by published protocols [49-52] or listing on public registries, such as clinicaltrials.gov. Evidence is broader for SSI than for dehiscence or LOS, and it has not yet been possible to individually analyze for superficial, deep, or organ space SSI.

\section{Conclusion}

This is the first comprehensive meta-analysis that has assessed the benefit of a specific brand of single-use NPWT on SSCs. It showed a clear and significant reduction in SSIs, wound dehiscence, and LOS by application of the PICO single-use NPWT system used prophylactically on a closed surgical incision when compared with standard care.

\section{Acknowledgments}

$\diamond$ Trademark of Smith \& Nephew.

We gratefully acknowledge Colin Peirce and Peter O'Leary, who provided additional data not found in the article [30] (SD of LOS).

We gratefully acknowledge Nana Hyldig, who gave us permission to use her $\mathrm{PhD}$ Thesis [35] with interim results before her publishing the full RCT results.

We used comprehensive abstract and poster data of studies currently in submission $[30,37]$.

\section{Author Disclosure Statement}

VS and RM are employees of Smith \& Nephew plc.

\section{References}

1. Sugrue M, Ciprandi G, Djohan R, et al. World Union of Wound Healing Societies (WUWHS) Consensus Document. Closed surgical incision management: Understanding the role of NPWT. Wounds Int [Internet]. 2016. www .woundsinternational.com/wuwhs/view/consensus-documentclosed-surgical-incision-management-understanding-the-roleof-npwt. (Last accessed July 29, 2017).

2. Mangram AJ, Horan TC, Pearson ML, et al. Guideline for prevention of SSI, 1999. Infect Control Hosp Epidemiol 1999;20:250-278.

3. Tanner J, Padley W, Assadian O, et al. Do surgical care bundles reduce the risk of surgical site infections in patients undergoing colorectal surgery? A systematic review and cohort meta-analysis of 8,515 patients. Surgery $2015 ; 158$ : 66-77.

4. Leaper DJ, Tanner J, Kiernan M, et al. Surgical site infection: Poor compliance with guidelines and care bundles. Int Wound J 2015;12:357-362.

5. Hyldig N, Birke-Sorensen H, Kruse M, et al. Meta-analysis of negative-pressure wound therapy for closed surgical incisions. Br J Surg 2016;103:477-486.

6. Karlakki S, Brem M, Giannini S, et al. Negative pressure wound therapy for management of the surgical incision in orthopaedic surgery: A review of evidence and mechanisms for an emerging indication. Bone Joint Res 2013;2:276284.

7. Allegranzi B, Bischoff $\mathrm{P}$, de Jonge $\mathrm{S}$, et al. New WHO recommendations on preoperative measures for surgical site infection prevention: An evidence-based global perspective. Lancet Infect Dis 2016;16:e276-287.

8. Nordmeyer M, Pauser J, Biber R, et al. Negative pressure wound therapy for seroma prevention and surgical incision treatment in spinal fracture care. Int Wound J 2016;13: 1176-1179.

9. Argenta LC, Morykwas MJ. Vacuum-assisted closure: A new method for wound control and treatment: Clinical experience. Ann Plast Surg 1997;38:563-576. 
10. Young SR, Hampton S, Martin R. Non-invasive assessment of negative pressure wound therapy using high frequency diagnostic ultrasound: Oedema reduction and new tissue accumulation. Int Wound J 2013;10:383-388.

11. Webb LX, Pape HC. Current thought regarding the mechanism of action of negative pressure wound therapy with reticulated open cell foam. J Orthop Trauma 2008;22(Suppl 10):S135-137.

12. Sandy-Hodgetts K, Watts R. Effectiveness of negative pressure wound therapy/closed incision management in the prevention of post-surgical wound complications: A systematic review and meta-analysis. JBI Database System Rev Implement Rep 2015;13:253-303.

13. Ingargiola MJ, Daniali LN, Lee ES. Does the application of incisional negative pressure therapy to high-risk wounds prevent surgical site complications? A systematic review. Eplasty 2013;13:e49.

14. Webster J, Scuffham P, Stankiewicz M, et al. Negative pressure wound therapy for skin grafts and surgical wounds healing by primary intention. Cochrane Database Syst Rev 2014;4:CD009261.

15. De Vries FE, Wallert ED, Solomkin JS, et al. A systematic review and meta-analysis including GRADE qualification of the risk of surgical site infections after prophylactic negative pressure wound therapy compared with conventional dressings in clean and contaminated surgery. Medicine (Baltimore) 2016;95:e4673.

16. Semsarzadeh NN, Tadisina KK, Maddox J, et al. Closed incision negative-pressure therapy is associated with decreased surgical-site infections: A meta-analysis. Plast Reconstr Surg 2015;136:592-602.

17. Liberati A, Altman DG, Tetzlaff J, et al. The PRISMA statement for reporting systematic reviews and metaanalyses of studies that evaluate healthcare interventions: Explanation and elaboration. BMJ 2009;339:b2700.

18. Mantel N, Haenszel W. Statistical aspects of the analysis of data from retrospective studies of disease. J Natl Cancer Inst 1959;22:719-748.

19. Higgins J, Green S (eds). Cochrane Handbook for Systematic Reviews of Interventions Version 5.1.0 [updated March 2011]. The Cochrane Collaboration, 2011. www .cochrane-handbook.org.

20. Anderson V, Chaboyer W, Gillespie B, Fenwick J. The use of negative pressure wound therapy dressing in obese women undergoing caesarean section: A pilot study. Evid Based Midwifery 2014;12:23-28.

21. Bonds AM, Novick TK, Dietert JB, et al. Incisional negative pressure wound therapy significantly reduces surgical site infection in open colorectal surgery. Dis Colon Rectum 2013;56:1403-1408.

22. Bullough L. Incision management with negative pressure wound therapy: A new mode of action? Wound Essentials 2015;10:14-18.

23. Bullough L, Burns S. Reducing C-section wound complications. Clin Serv J 2015;April:2-6.

24. Hickson E, Harris J, Brett D. A journey to zero: Reduction of post-operative cesarean surgical site infections over a five-year period. Surg Infect 2015;16:174-177.

25. Pellino G, Sciaudone G, Candilio G, et al. Effects of a new pocket device for negative pressure wound therapy on surgical wounds of patients affected with Crohn's disease: A pilot trial. Surg Innov 2014;21:204-212.

26. Tuffaha HW, Gillespie BM, Chaboyer W, et al. Cost-utility analysis of negative pressure wound therapy in high-risk cesarean section wounds. J Surg Res 2015;195:612-622.
27. Heard C, Chaboyer W, Anderson V, et al. Costeffectiveness analysis alongside a pilot study of prophylactic negative pressure wound therapy. J Tissue Viability 2017;26:79-84.

28. Adogwa O, Fatemi P, Perez E, et al. Negative pressure wound therapy reduces incidence of postoperative wound infection and dehiscence after long-segment thoracolumbar spinal fusion: A single institutional experience. Spine $\mathbf{J}$ 2014;14:2911-2917.

29. Chaboyer W, Anderson V, Webster J, et al. Negative pressure wound therapy on surgical site infections in women undergoing elective caesarean sections: A pilot RCT. Healthcare 2014;2:417-428.

30. Galiano R, Djohan R, Shin J, Hudson D, Van der Hulst R, Beugels $J$, et al. The effects of a single use canister-free NPWT system on the prevention of postsurgical wound complications in patients undergoing bilateral breast reduction surgery. Presented at: BAAPs Annual Scientific Meeting; September 25-26, 2014; London, United Kingdom.

31. Gillespie BM, Rickard CM, Thalib L, et al. Use of negative-pressure wound dressings to prevent surgical site complications after primary hip arthroplasty: A pilot RCT. Surg Innov 2015;22:488-495.

32. Hasselmann J, Kuhne T, Acosta S. Negative pressure wound therapy in the prevention of groin infections after vascular surgery. In: Proceedings from the EWMA, May 11-13; 2016; Bremmen, Germany; p. 54.

33. Hester T, Mahmood S, Moftah F. Is single use portable incisional negative pressure wound therapy system suitable for revision arthroplasty ? Adv Orthop Surg 2015;2015: Article ID 247324, 4 pages.

34. Holt R, Murphy J. PICO ${ }^{\mathrm{TM}}$ incision closure in oncoplastic breast surgery: A case series. Br J Hosp Med 2015;76:217223.

35. Hyldig N. Incisional Negative Pressure Wound Therapy: The Clinical Effect on Post-Caesarean Wound Complications in Obese Women. Odense: University of Southern Denmark, 2016.

36. Karlakki SL, Hamad AK, Whittall C, et al. Incisional negative pressure wound therapy dressings (iNPWTd) in routine primary hip and knee arthroplasties: A randomised controlled trial. Bone Joint Res 2016;5:328-337.

37. Luciani D, Mazzotti A, Capra P, Giannini S. Efficacy of PICO negative pressure wound therapy (NPWT) versus traditional dressing for the treatment of postoperative wound care management in hip and knee revision surgery: A randomized controlled trial. In: Proceedings of the WUWHS Congress; September 25-29, 2016; Florence, Italy; p. OR 111.

38. Matsumoto T, Parekh SG. Use of negative pressure wound therapy on closed surgical incision after total ankle arthroplasty. Foot Ankle Int 2015;36:787-794.

39. O'Leary DP, Peirce C, Anglim B, et al. Prophylactic negative pressure dressing use in closed laparotomy wounds following abdominal operations: A randomized, controlled, open-label trial: The P.I.C.O. Trial. Ann Surg 2017;265: 1082-1086.

40. Pellino G, Sciaudone G, Candilio G, et al. Preventive NPWT over closed incisions in general surgery: Does age matter? Int J Surg 2014;12(Suppl 2):S64-S68.

41. Selvaggi F, Pellino G, Sciaudone G, et al. New advances in negative pressure wound therapy (NPWT) for surgical wounds of patients affected with Crohn's disease. Surg Technol Int 2014;24:83-89. 
42. Tuuli MG, Martin S, Stout MJ, et al. 412: Pilot randomized trial of prophylactic negative pressure wound therapy in obese women after cesarean delivery. Am J Obstet Gynecol 2017;216:S245-S245.

43. Uchino M, Hirose K, Bando T, et al. Randomized controlled trial of prophylactic negative-pressure wound therapy at ostomy closure for the prevention of delayed wound healing and surgical site infection in patients with ulcerative colitis. Dig Surg 2016;33:449-454.

44. Witt-Majchrzak A, Żelazny P, Snarska J. Preliminary outcome of treatment of postoperative primarily closed sternotomy wounds treated using negative pressure wound therapy. Pol Przegl Chir 2015;86:456-465.

45. Beecher SM, O'Leary DP, McLaughlin R, et al. Influence of complications following immediate breast reconstruction on breast cancer recurrence rates. Br J Surg 2016;103: 391-398.

46. Artinyan A, Orcutt ST, Anaya DA, et al. Infectious postoperative complications decrease long-term survival in patients undergoing curative surgery for colorectal cancer: A study of 12,075 patients. Ann Surg 2015;261: 497-505.

47. Kerin Povšič M, Ihan A, Beovič B. Post-operative infection is an independent risk factor for worse long-term survival after colorectal cancer surgery. Surg Infect 2016; 17:700-712.

48. Nherera LM, Trueman P, Karlakki SL. Cost-effectiveness analysis of single-use negative pressure wound therapy dressings (sNPWT) to reduce surgical site complications (SSC) in routine primary hip and knee replacements. Wound Repair Regen 2017 Epub ahead of print.
49. Arundel C, Buckley $\mathrm{H}$, Clarke E, et al. Negative pressure wound therapy versus usual care for Surgical Wounds Healing by Secondary Intention (SWHSI trial): Study protocol for a randomised controlled pilot trial. Trials 2016;17:535.

50. Gillespie BM, Webster J, Ellwood D, et al. ADding negative pRESSure to improve healING (the DRESSING trial): A RCT protocol. BMJ Open 2016;6:e010287.

51. Sandy-Hodgetts K, Leslie GD, Parsons R, et al. Prevention of postsurgical wound dehiscence after abdominal surgery with NPWT: a multicentre randomised controlled trial protocol. J Wound Care 2017;26(Suppl 2):S23-S26.

52. Hasselmann J, Kühme T, Björk J, Acosta S. Incisional negative pressure wound therapy in the prevention of surgical site infection after vascular surgery with inguinal incisions: Rationale and design of a randomized controlled trial ( INVIPS-Trial). Surg Sci 2015;6:562-571.

53. Hudson DA, Adams KG, Huyssteen A Van, et al. Simplified negative pressure wound therapy: Clinical evaluation of an ultraportable, no-canister system. Int Wound J 2015; 12:195-201.

Address correspondence to: Dr. Robin Martin Advanced Wound Management, Clinical, Scientific and Medical Affairs Smith \& Nephew plc 101 Hessle Road Hull, HU3 2BN United Kingdom

E-mail: robin.martin@smith-nephew.com 